\title{
BIR ÜNIVERSITE KLINIĞiNDE BIPOLAR BOZUKLUK TANISI ILE IZLENEN YAŞLI HASTALARDA FARMAKOLOJIK TEDAVI SEÇIMLERININ INCELENMESI
}

\author{
Umut Altunöz*, Rifat Serav İlhan*, Ezgi Hatip*, Murat Çiçeklidağ, Mahmut Altaş*, Burcu Gümüştekin*, \\ Ahmet Kakaç*, Erguvan Tuğba Özel KızıI**
}

\section{ÖZET}

Amaç: Bu çalışmanın amacı bipolar bozukluğu (BB) olan yaşlı hastalarda tercih edilen psikofarmakolojik tedavileri, görülen başlıca yan etkileri ve ilaç uyumunu ilişkin yazın ışığında ortaya koymaktır.Yöntem: Çalışmanın örneklemini bir üniversite hastanesi psikiyatri kliniğine 2006-2011 yılları arasında başvuran BB Tip 1 tanısı almış, 65 yaş ve üzerinde olan 99 yaşlı hasta oluşturmuştur. Hastaların dosyaları incelenmiş ve her hastanın son kontrolünde kullanmakta olduğu ilaçlar, yan etkiler ve ilaç uyumu değerlendirilmiştir.Bulgular: Hastaların \%74.4'ü duygudurum düzenleyici (DDD), \%71.7'si ikinci kuşak antipsikotik (IKKAP), \%36.4'ü hipnotik-sedatif ilaç, \%27.2'si ise antidepresan kullanmaktadır. DDD olarak en sık lityum (\%37.4) ve valproik asit (\%36.4) tercih edilmiştir. Hastaların \%77.7'sinde kombinasyon tedavisi, \%22.3'ünde monoterapi tercih edilmiştir. En sık (\%41.4) $D D D+I K A P$ kombinasyonu, IKAP olarak da hem kombine hem de monoterapide en sık ketiyapin (\%41.4) kullanılmaktadır. Bildirilen başlıca yan etkiler tremor, iştah artışı, hipersomni, unutkanlık, ekstrapiramidal yan etkiler, gastrointestinal sistem yakınmaları, halsizlik, kilo artışı, baş ağrısıdır. Ilaç

* Araş. Gör., Ankara Üniversitesi Tıp Fakültesi, Ruh Sağlığı ve Hastalıkları Anabilim Dalı

** Doç. Dr., Ankara Üniversitesi Tıp Fakültesi, Ruh Sağlığı ve Hastalıkları Anabilim Dalı, Geriyatrik Psikiyatri Birimi uyumu açısından hastaların \%8.1'i tam uyumlu, \%54.5'i uyumlu, \%31.3'ü kısmen uyumlu, \%6'sı tam uyumsuz olarak değerlendirilmiştir. Sonuçlar: $B u$ çalışma Türkiye'de yaş/ı BB hastalarında ilaç tedavisi seçeneklerini değerlendiren ilk çalışmadır. Sıklıkla kombinasyon tedavilerinin tercih edildiğini, $D D D$ olarak lityumun valproik asit kadar sık kullanıldığını ve IKAP kullanımının yaygın olup en fazla ketiyapinin tercih edildiğini ortaya koymuştur. Hastaların \%62.6'sının tedavi uyumunun iyi olduğu saptanmıştır. $B u$ sonuçlar yaşlı ve genç $B B$ hastalarında yürütülen diğer çalışmalara benzerdir. Yaşlı BB tedavisi ile ilgili uzunlamasına kontrollü çalışmalara ve bu çalışmaların sonuçları ile oluşturulacak tedavi kılavuzlarına intiyaç vardır.

Anahtar Kelimeler: antipsikotikler, bipolar bozukluk, geriyatrik psikiyatri, psikofarmakoloji.

\section{Evaluating Pharmacological Treatment Options in Elderly Patients With Bipolar Disorder Who Admitted to a University Hospital}

\section{ABSTRACT}

Objective: The aim of the present study is to evaluate pharmacological treatment options, common side effects and treatment compliance in elderly patients with type I Bipolar Disorder (BD) in the light of current literature. Method: The study sample ( $n=99)$ consisted of elderly patients $(\geq 65$ years old) who admitted to the psychiatry clinic of a 
university hospital between 2006-2011 and had the diagnosis of $B D$ type-1. The patient files were examined and psychotropic agents which were used in the last visit were taken into account. Common side effects and treatment compliance were also evaluated. Results: Mood stabilisers (MS) were used by $74.4 \%$ of the patients, followed by second generation antipsychotics (SGAP) (71.7\%), hypnotic-sedative agents (36.4\%) and andantidepressants (\%27.2). Most commonly used MS were lithium (37.4\%) and valproic acid (36.4\%). $77.7 \%$ of the patients were on combination therapy, whereas $22.3 \%$ of them were on monotherapy. The most common combination was MS+SGAP (41.4\%) and quetiapine was the most commonly used SGAP $(41.4 \%)$. Tremor, increase in apetite, hypersomnia, forgetfulness, extrapyramidal side effects, gastrointestinal complaints, defatigation, weight gain and headache were the most commonly declared side effects. $8.1 \%$ of the patients were fully compliant, $54.5 \%$ were compliant, $31.3 \%$ were partially compliant and $6 \%$ were noncompliant to the treatment. Conclusions: This is the first study in Turkey which evaluated pharmacological treatment options in elderly patients with BD. This study emphasized that combination treatments were commonly preferred, lithium usage was as common as valproic acid, SGAP drugs were frequently preferred and the most common one was quetiapine. $62.6 \%$ of the patients had good compliance to the treatment. These results were consistent with previous studies on elderly and young $B D$ patients. Prospective studies about the treatment of $B D$ in the elderly and treatment guidelines in accordance with them are needed.

Key words: antipsychotics, bipolar disorder, geriatric psychiatry, psychopharmacology

\section{GíRiş}

Erişkin popülasyonda bipolar bozukluk (BB) \%1 civarında görülürken (Regier ve ark. 1993), yaşlılıkta başlayan BB için yaşam boyu yaygınlık epidemiyolojik çalışmalarda \%0.1 (Hirschfeld ve ark. 2003; Unutzer ve ark. 1998) bakım evlerinde ve klinik başvurularda ise \%10'a varan oranlarda bildirilmiştir (Depp ve Jeste 2004). Yaşlılarda BB'nin klinik görünümü, seyri, etiyopatogenezi ve tedavisi konusunda az sayıda çalışmaya rastlanmaktadır (Vasudev ve Thomas 2010).

Erişkinlerde BB'nin erken başlangıçlı (<50 yaş) ve geç başlangıçlı ( $\geq 50$ yaş) şeklinde iki ayrı tipe ayrılmasının geçerli bir yaklaşım olabileceğine ilişkin bulgular ağırlık kazanmaktadır (Depp ve Jeste 2004; Moorhead ve Young 2003; Vasudev ve Thomas 2010). Erken başlangıçlı tipte ailesel geçişin daha sık olduğu, manik belirtilerin daha sık görüldüğü ve şiddetli seyrettiği, geç başlangıçlı tipte ise demans ve serebrovasküler hastalık gibi nörolojik eştanıların bulunduğu bildirilmiştir (Depp ve Jeste 2004; Sajatovic 2002; Subramaniam ve ark. 2008).

Literatürde çalışma sayısı az olmasına rağmen, yaşlılarda BB'nin gençlerdeki BB'den etiyopatogenez, epidemiyoloji, klinik görünüm ve prognoz açısından farklı olabileceği yönünde tartışmalar bulunmaktadır (Aizenberg ve ark. 2006; Lala ve Sajatovic 2012; Oostervink ve ark. 2009; Young ve ark. 2007). Ayrıca yaşlıların genel olarak ilaçları metabolize etme kapasitesi azalmış, yan etkilere duyarlılıkları artmıştır (Ritchie 2008). $\mathrm{Bu}$ nedenlerle bu hasta grubunda gençlerdekinden farklı tedavi seçenekleri ya da ilaç dozları gerekli olabilir (Aziz ve ark. 2006).

Yaşlılarda BB tedavisinin etkinliğini araştırmayı hedefleyen randomize kontrollü bir çalışma bulunmamaktadır (Gildengers ve ark. 2005; Young ve ark. 2010; Gildengers ve ark. 2012). Geriye dönük yapılan geniş örneklemli çalışmalar yaşlıların gençlere göre bazı ilaçları daha düşük dozlarda kullandıklarını göstermektedir (Al Jurdi ve ark. 2008). Klinik uygulamalar; deneyim, açık etiketli ve natüralistik örneklemlerle yapıımış çalışmalar, olgu bildirimleri ve genç hastalar ile yapılmış çalışmaların sonuçlarına dayanmakta olup, yaşlılarda BB tedavisine özgü bir tedavi algoritması yoktur (Aziz ve ark. 2006; Bhalerao ve ark. 2012; Young ve ark. 2010).

Ülkemizde geriyatrik psikiyatri çalışmaları son yıllarda hız kazanmakla beraber, yaşlılarda $B B$ ve tedavisi ile ilgili bir çalışmaya rastlanmamıştır. Bu çalışmanın amaç yaşlı BB hastalarında tercih edilen psikofarmakolojik tedavileri, görülen başlıca yan etkileri ve ilaç uyumunu ortaya koymaktır. Bu amaçla bir üniversite hastanesine bağlı Psikiyatri kliniğinde son beş yılda Tip 1 BB tanısı ile 
izlenen yaşlı hastaların ( $\geq 65$ yaş) kullanmakta oldukları psikofarmakolojik ilaçlar, tedavilerin yan etkileri ve ilaç uyumu geriye dönük olarak değerlendirilmiş, elde edilen veriler mevcut literatür bilgileri ışığında gözden geçirilmiştir.

\section{YÖNTEM}

$\mathrm{Bu}$ çalışmanın örneklemini bir üniversite hastanesi psikiyatri anabilim dalına 2006-2011 yıllar arasında başvuran Bipolar Bozukluk Tip 1 (ICD-10 sınıflandırmasına göre F31 ve alt kırılımları dahil, F31.8-BB Tip 2 hariç) tanısı almış, 65 yaş ve üzerinde olan hastalar oluşturmuştur. Hastane veri tabanı taranarak 99 hastanın dosyasına ulaşılmıştır. Hastaların dosyaları aynı psikiyatrist tarafından standardize bir veri formu kullanılarak değerlendirilmiştir. Her hastanın son kontrolünde kullanmakta olduğu ilaçlar dikkate alınmıştır. BB tedavisinde kullanılan ana ilaçlar dışında sedasyon sağlamak amaçı, kısa süreli olarak verilen ek tedaviler analize alınmamıştır. Bunlar benzodiyazepinler ve sedatif-hipnotik amaçla kullanılan antidepresanlardır (örn. Trazodon 50-100 mg/gün gibi).

Hastaların kullanmakta olduğu ilaçların yanı sıra geçirilen son hastalık atağı ve bildirilen yan etkiler de değerlendirilmiştir. İlaç uyumu dosyaya hekim tarafından not edilen bilgilere dayanarak aynı psikiyatrist tarafından tam uyumlu (ilacını her gün düzenli olarak alıyor), uyumlu (ilacını haftada birden az olmak kaydıyla ara sıra almayı unuttuğu oluyor), kısmen uyumlu (ilacını haftada birden fazla kez olmak kaydıyla bazen almayı unutuyor), tam uyumsuz (ilacını hemen hemen hiç düzenli kullanmıyor) şeklinde sayısallaştırıımıştır.

\section{İstatistiksel Analiz}

Hastaların çeşitli sosyodemografik özellikleri (cinsiyet, son hastalık atağı vb.) ve ilaç kullanım sıklıkları için tanımlayıcı istatistikler yapılmış; frekans ve yüzde değerleri hesaplanmıştır. Yaşlı $(n=87)$ ve çok yaşı $(n=12)$ hastalar arasında ikinci kuşak antipsikotik (IKAP), lityum ( $\mathrm{Li}$ ) ve valproik asit (VA) kullanımı açısından fark olup olmadığına Fisher'in kesin ki-kare testi kullanılarak bakılmıştır.

\section{BULGULAR}

Hastaların yaşları 65 ile 89 arasındadır (ortanca 69). Hastaların 53'ü (\%53.5) kadın, 46'sı (\%46.5) erkektir. Geçirilen son hastalık atağı; 46'sında (\%46.5) depresif, 35 hastada manik (\%35.3), 13'ünde (\%13.1) hipomanik ve 5 'inde (\%5) karma ataktır.

Hastaların BB tedavisi için kullandıkları ortalama ilaç sayısı $1.83^{\prime}$ 'tür ( $\mathrm{ss}=0.5$, en düşük=1, en yüksek=3). Üç ilaç kullanan hasta sayısı 5 'tir. Tablo 1 'de hastaların kullandıkları ilaç grupları özetlenmiştir. Hastaların 22'si (\%22.3) monoterapi, 77'si (\%77.7) kombine tedavi almaktadır.

Tablo 1: Hastaların kullanmakta oldukları ilaç grupları

\begin{tabular}{lcc}
\hline & $\mathbf{N}$ & $\mathbf{\%}$ \\
Monoterapi & 22 & 22.3 \\
DDD & 7 & 7.1 \\
IKAP & 15 & 15.1 \\
Kombinasyon terapisi & 77 & 77.7 \\
DDD+DDD & 9 & 9.1 \\
DDD+IKAP & 41 & 41.4 \\
DDD+AD & 12 & 12.1 \\
DDD+IKAP+AD & 5 & 5.0 \\
IKAP+AD & 10 & 10.1 \\
Toplam & 99 & $\mathbf{1 0 0 . 0}$ \\
\hline
\end{tabular}

DDD: Duygu Durum Düzenleyici, IKAP:İkinci Kuşak Antipsikotik, AD:Antidepresan 
Hastaların kullanmakta oldukları ilaçlar Tablo 2'de verilmiştir. 74 hasta (\%74.4) duygudurum düzenleyici ilaç (DDD), 71 hasta (\%71.7) IKAP, 27 hasta (\%27.2) antidepresan (AD), 36 hasta ise (\%36.4) hipnotik-sedatif ilaç kullanmaktadır. 9 hasta $(\% 9.1)$ ikili DDD tedavi almaktadır. Bunların 4'ü Li ve VA (\%4), 4'ü Li ve lamotrijin (\%4), ${ }^{\prime} \mathrm{i}$ ise VA ve lamotrijin (\%1) kullanmaktadır. Birinci kuşak antipsikotik (BKAP) ve trisiklik antidepresan kullanan hasta bulunmamaktadır. Monoterapi olarak AD ilaç alan hasta da yoktur.

Tablo 2: Gruplarına göre hastaların kullanmakta oldukları ilaçlar

\begin{tabular}{|c|c|c|}
\hline & $\mathbf{N}$ & $\%$ \\
\hline \multicolumn{3}{|c|}{ Duygudurum Düzenleyiciler } \\
\hline Lityum & 37 & 37.4 \\
\hline Valproik Asit & 36 & 36.4 \\
\hline Karbamazepin & 2 & 2.0 \\
\hline Lamotrijin & 7 & 7.0 \\
\hline \multicolumn{3}{|c|}{ İkinci Kuşak Antipsikotikler } \\
\hline Ketiyapin & 41 & 41.4 \\
\hline Olanzapin & 14 & 14.1 \\
\hline Risperidon & 12 & 12.1 \\
\hline Aripiprazol & 2 & 2.0 \\
\hline Klozapin & 2 & 2.0 \\
\hline Amisülpirid & 1 & 1.0 \\
\hline \multicolumn{3}{|l|}{ Antidepresanlar } \\
\hline \multicolumn{3}{|l|}{ SSGI } \\
\hline Sertralin & 11 & 11.1 \\
\hline Essitalopram & 4 & 4.0 \\
\hline Paroksetin & 2 & 2.0 \\
\hline Fluvoksamin & 1 & 1.0 \\
\hline \multicolumn{3}{|l|}{ SNGI } \\
\hline Venlafaksin & 6 & 6.1 \\
\hline Duloksetin & 1 & 1.0 \\
\hline \multicolumn{3}{|l|}{ Atipik } \\
\hline Mirtazapin & 3 & 3.0 \\
\hline \multicolumn{3}{|c|}{ Sedatifler/Hipnotikler } \\
\hline Trazodon & 9 & 9.1 \\
\hline Klonazepam & 10 & 10.1 \\
\hline Alprazolam & 7 & 7.1 \\
\hline Lorazepam & 5 & 5.0 \\
\hline Zopiklon & 5 & 5.0 \\
\hline
\end{tabular}

SSGi: Seçici Serotonin Gerialım İnhibitörü, SNGi: Seçici Serotonin Noradrenalin Gerialım İnhibitörü

Yaşı ( $n=87)$ ve çok yaşlı (80 yaş ve üzeri) $(n=12)$ hastalar IKAP kullanımı açısından karşılaştırıımış ve fark bulunmamıştır $(n=62$, $\% 71.2 ; n=9, \% 75)(p=0.54)$. Yaşlı ve çok yaşlı gruplar arasında $\mathrm{Li}(\mathrm{n}=33, \% 38 ; \mathrm{n}=4 \% 33)$ ve VA ( $n=33, \% 38 ; n=3, \% 25)$ kullanımı açısından da fark yoktur (Li için $p=0.51$; VA için $p=0.3$ ).

Hastaların en sık kullandıkları AD ilaçlar seçici serotonin gerialım inhibitörleridir (SSGi)
(\%18.1). Hipnotik-sedatif olarak da en sık benzodiyazepinler tercih edilmiştir (\%23).

59 (\%59.6) hastanın kayıtlarında yan etki bildirimi mevcuttur. Bildirilmiş olan yan etkiler Tablo 3'te verilmiştir. 4 hastada (\%4) hipotiroidi, 4 hastada ise (\%4) lityum intoksikasyonu öyküsü mevcuttur. 
Tablo 3: Bildirilen yan etkiler

\begin{tabular}{lcc}
\hline & $\mathbf{N}$ & $\%$ \\
Tremor & 18 & 18.2 \\
İştah artışı & 13.1 \\
Hipersomni & 13 & 12.1 \\
Unutkanlık & 12 & 12.1 \\
Ekstapiramidal yan etkiler & 11.1 \\
Gastrointestinal sistem yakınmaları & 12 & 10.1 \\
Halsizlik & 11 & 9.1 \\
Kilo artışı & 10 & 8.1 \\
Baş ağısı & 9 & 6.1 \\
İşahta azalma & 8 & 6.1 \\
Ődem & 6 & 4.0 \\
Cinsel disfonksiyon & 6 & 3.0 \\
Çarpıntı & 4 & 3.0 \\
Hipotansiyon & 3 & 3.0 \\
Ağız kuruluğu & 3 & 3.0 \\
Diğer (kaşıntı, saç dökülmesi, kilo kaybı, fotofobi, ellerde uyuşma, & 7.1 \\
idrar retansiyonu) & 3 & 3 \\
\hline
\end{tabular}

İlaç uyumuna ilişkin yapılan değerlendirmede hastaların 8'i (\%8.1) tam uyumlu, 54'ü (\%54.5) uyumlu, 31'i (\%31.3) kısmen uyumlu, 6'sı (\%6) tam uyumsuz olarak değerlendirilmiştir.

\section{TARTIŞMA}

$\mathrm{Bu}$ çalışmada yaşlılarda BB tedavisinde sıklıkla kombinasyon tedavisinin tercih edildiği (\%77.7) ve çoğunlukla DDD ile İKAP kombinasyonunun (tüm hastaların \%41.4'ü) kullanıldığı saptanmıştır. Hastaların \%74.7'ü DDD, \%71.7'si İKAP, \%27.2'si ise AD kullanmaktadır. Geriye dönük yapılan başka bir çalışmada da benzer sonuçlar elde edilmiş, 138 yaşlı BB hastasında kombinasyon tedavilerinin monoterapiden daha sık tercih edildiği (sırasıyla \%57 ve \%38), en fazla DDD ilaçların reçete edildiği (\%68), bunu antipsikotik (AP) (\%54) ve AD ilaçların (\%34) izlediği bildirilmiştir (Beyer ve ark. 2008).

Çalışmadaki hastaların BB tedavisi için kullandıkları ortalama ilaç sayısı 1.83 olup, bu sayı Al Jurdi ve arkadaşlarının, STEP-BD çalışmasında hastalıklarında düzelme görülen yaşlı ve genç hastaların kullandıkları ilaçları karşılaştırdıkları çalışma ile benzerdir (2.06) (Al Jurdi ve ark. 2008). Aynı çalışmada genç BB hastalarının kullandıkları ortalama ilaç sayısı 2.05 olup yaşlılardan farklı değildir. Bu sonuçlar yaşlılarda klinik uygulamalarda polifarmasiden kaçınılması açısından önemlidir. Çünkü ilaç-ilaç etkileşimleri yaşlılarda daha sık olabilmekte, ayrıca yan etki sıklığı ve ciddiyeti de yaşla artmaktadır (Onder ve ark. 2002; Pollock ve ark. 1999).

$\mathrm{Bu}$ çalışmada sıklıkla DDD+iKAP kombinasyonunun kullanıldığı görülmüştür (\%41.4), ikili DDD kullanımı ise nadir bulunmuştur (\%9.1). BB tedavisi güç bir hastalık olup, tedavi kılavuzları monoterapiden yana olsa da klinik pratikte kombinasyon tedavileri sıklıkla kullanılmaktadır (Fountoulakis ve ark. 2005). BB'de kombinasyon tedavilerinin (DDD+IKAP, DDD+DDD), DDD monoterapisinden daha etkin olduğunu bildiren çalışmalar bulunmaktadır (BALANCE 2010; Houston ve ark. 2009; Suppes ve ark. 2009). BB için kombinasyon tedavilerini birbiri ile karşılaştıran çalışmalar oldukça azdır. Bir çalışmada Li tedavisi altındayken hipomanik kayma geçiren hastalara VA veya olanzapin eklenmesinin etkinlik açısından bir farkı olmadığı, ancak olanzapin ile semptomların daha hızlı remisyona girdiği gösterilmiştir (Maina ve ark. 2007). Hem yaşlı hem genç BB tedavisinde kombinasyon tedavilerini birbiri ile karşılaştıran çalışmalara ihtiyaç vardır.

$\mathrm{Bu}$ çalışmada yaşlılarda DDD olarak sıklıkla Li veya VA kullanıldığı ve bu iki ilacın neredeyse eşit oranda tercih edildiği görülmüştür (\%37.4/\%36.4). Kanada'da 1993 
ile 2001 yılları arasında hastaneye başvurmuş ve yeni ilaç başlanmış 9243 yaşlı BB hastasıyla yapılan bir çalışma klinisyenlerin zaman içinde Li yerine VA'yı tercih ettiklerini göstermiştir (Shulman ve ark. 2003). Al Jurdi ve arkadaşlarının (2008) yaşı BB örnekleminde hastaların \%39.4'ünün $V A$, $\% 29.5$ 'inin Li kullandığı ortaya konmuştur. Beyer ve arkadaşlarının (2008) yaşlı BB hastalarında geriye dönük olarak ilaç tercihlerini inceledikleri çalışmalarında $\mathrm{Li} \% 24$ oranında kullanılırken, VA kullanım oranı \%33'tür. Yani, önceki çalışmaların sonuçları yaşlı BB hastalarında VA kullanımının Li'ye kıyasla daha fazla olduğu yönündedir.

$\mathrm{Li}$ neredeyse tüm kanıta dayalı tedavi kılavuzlarında BB mani dönemi tedavisi ve profilakside ilk seçenek ilaç olarak yer almaktadır (Fountoulakis ve Vieta 2008; Suppes ve ark. 2005; Yatham ve ark. 2006). Yaşlı BB hastalarında herhangi bir DDD ile yapıımış uzunlamasına kontrollü bir çalışma bulunmamaktadır (Shulman 2010). Yaşlılarda glomerüler filtrasyon hızı azalacağından Li'nin böbrekten atılımı da azalacaktır, ayrıca yaşılıarın sık kullandıkları antienflamatuvar ilaçlar, asetilkolinesteraz inhibitörleri, tiyazid diüretikleri Li kan düzeyini yükseltebilirler (Aziz ve ark. 2006). Bu çalışmada 4 hastada (\%4) Li entoksikasyonu not edilmiştir. Sürekli lityum tedavisi altında olan 10.615 yaşlı hastanın alındığı çok merkezli bir vaka-kontrol çalışmasında da hastaların \%4'ünün on yıllık süre içerisinde en az bir kez lityum entoksikasyonu ile hastaneye başvurduğu bildirilmiştir (Juurlink ve ark. 2004). Yaşılıarda terapötik kan düzeylerine daha düşük lityum dozlarında ulaşılabildiği bildirilmekte ve erişkin terapötik kan düzeyinden daha düşük kan düzeyleri ile tedavinin sürdürülmesi önerilmektedir (Young 2005). VA'nın yaşlılarda lityuma göre tolere edilmesinin daha iyi olabileceği bildirilmektedir (Aziz ve ark. 2006; Young ve ark. 2004). Bu nedenle, önceki çalışmalarda VA kullanım oranları Li'dan daha fazla bulunmuş olabilir.

STEP-BD çalışmasında tedaviye yanıt veren yaşlı $B B$ hastalarının \%21.2'si lamotrijin kullanmaktadır (Al Jurdi ve ark. 2008). Yaşlı BB'de geriye dönük olarak ilaç tedavilerinin çalışıldığı bir başka çalışmada ise bu oran \%11'dir (Beyer ve ark. 2008). Yaşlı BB hastalarında depresif dönemde tedaviye lamotrijin eklenmesinin etkinliğinin incelendiği çok merkezli ileriye dönük bir çalışmada lamotrijin tedavisinin depresif semptomlar, işlevsellik ve genel psikopatoloji üzerine olumlu etkileri bildirilmiştir (Sajatovic ve ark. 2011). Türkiye Psikiyatri Derneği (TPD) BB Sağaltım Kılavuzu mani ve akut dönemde depresyon tedavisi için lamotrijini ilk seçenekler arasında önermemektedir (Vahip 2010). Bu çalışmada da lamotrijiin kullanım oranı düşük (\%7) bulunmuştur.

Kardiyolojik ve nörolojik istenmeyen etkileri, kan diskrazilerine yol açabilmesi, mikrozomal enzim indüksiyonu ile ilaç-ilaç etkileşimine sık neden olması karbamazepinin yaşlılarda kullanımını kısıtlamaktadır (Aziz ve ark. 2006; Cares ve Powers 1998). Bu çalışmada da karbamazepin'in kullanım sıklığı düşük bulunmuştur (\%2), yaşlı örnekleminde yapılan başka çalışmalarda da bu oran $\% 6$ civarındadır (Al Jurdi ve ark. 2008; Beyer ve ark. 2008).

Çalışmadaki hastaların \%71.7'si IKAP kullanmaktadır. BKAP kullanan hasta yoktur. Literatürde yaş grubu gözetmeksizinyapılan çalışmalarda BB'de IKAP kullanım oranları $\% 32$ ile $\% 100$ arasında değişmekte olup (Ghaemi ve ark. 2006; Tohen ve Zarate 1998); yaşı BB örneklemli çalışmalarda bu oran \%30.6 (Al Jurdi ve ark. 2008), \%37.2 (Sajatovic ve ark. 2007), \%54 (Beyer ve ark. 2008) olarak bildirilmiştir. BKAP'ların yan etki profilleri ağır olduğundan yaşlılarda kullanımları tartışmalıdır (Schneeweiss ve ark. 2007; Wang ve ark. 2005). İKAP'lar daha düşük ekstrapiramidal sistem (EPS) yan etkileri ve tardif diskinezi riskine sahiptirler (Aziz ve ark. 2006). Olanzapin, risperidon, ketiyapin, ziprasidon ve aripiprazol FDA tarafından BB tedavisinde onay almışsa da, yaşlılarda BB'de kullanımları ile ilgili randomize kontrollü bir çalışma yoktur (Bhalerao ve ark. 2012; Sajatovic ve ark. 2008). Yaşlılarda demansa bağlı davranışsal ve psikolojik belirtilerde IKAP kullanımı ile mortalitenin arttığı birçok çalışma ile ortaya konduğundan Amerikan Gıda ve İlaç Dairesi (FDA) 2005 yılının Nisan ayında 
demansta tüm İKAP ilaçlar için kardiyovasküler mortaliteyi arttırdıklarına dair kara kutu uyarısında bulunmuştur. Ancak FDA'nın bu uyarısına temel oluşturan klinik çalışmaların hiçbiri yaşlı BB hastalarını içermemektedir (Schneider ve ark. 2005). Demans hastalarında kara kutu uyarsının yapılmasından sonraki yıllarda IKAP kullanımında yalnızca küçük bir azalma olduğu bildirilmiştir (Desai ve ark. 2012). Bu durum 2005 öncesinde de klinisyenlerin IKAP ilaçların olumsuz etkilerinin farkında olmaları ve dolayısı ile bu ilaçları zaten daha dikkatli reçetelemeleri yanısıra demansa bağıı davranışsal ve psikolojik belirtiler için FDA onaylı herhangi bir tedavi seçeneğinin olmamasına bağlı olabilir (Desai ve ark. 2012). Yeni yayınlanan bir çalışma yaşlı BB'de IKAP kullanımı ile mortalite riskini değerlendirmiş ve risperidonun en yüksek mortalite riskine sahip olduğunu bunu olanzapinin izlediğini, ketiyapinin en düşük riske sahip olduğunu ve bunun VA'nın mortalite riskine eşit olduğunu göstermiştir (Bhalerao ve ark. 2012). Bu çalışmada hem yaşlı grubun tamamında IKAP kullanım oranlarının yüksek olduğu, hem de hasta grubu yaşlı (65-79) ve çok yaşlı (80 ve üzeri) olarak ayrıldığında İKAP kullanım oranında bir fark olmadığı görünmektedir. Beyer ve arkadaşlarının (2008) çalışmasında da benzer bir sonuç bildirilmiştir. Bu sonuçlar, IKAP kullanımının bu yaş grubunda riskli olduğunun bildirilmesine karşın, klinik örneklemlerde tek başına DDD ilaçların ya da diğer ilaçlarla yapılan kombine tedavilerin yeterince etkin olmaması ile ilişkili olabilir.

Çalışmada en sık kullanılan İKAP'ın ketiyapin olduğu saptanmıştır (\%41.4). Bunu olanzapin (\%14.1) ve risperidon (\%12.1) izlemektedir. Yaşlı BB hastalarında mani döneminde ketiyapin tedavisini değerlendiren bir çalışma ketiyapin monoterapisinin manik belirtilerde hızlı ve güçlü bir düzelme sağladığını göstermiştir (Sajatovic ve ark. 2008). Ketiyapinin bipolar mani tedavisinde monoterapi olarak veya Li/VA ile kombine olarak kullanımı, ayrıca bipolar depresyon tedavisinde monoterapi olarak kullanımı, nükslerin önlenmesi için sürdürüm tedavisinde kullanımı ülkemizde ve birçok ülkede onay almıştır (Connolly ve Thase 2011; T.C. İlaç ve Eczacılık Genel Müdürlüğü 2012). Ketiyapin ortostatik hipotansiyon, antikolinerjik yan etkiler ve sedasyona yol açabilir (Aziz ve ark. 2006; Sajatovic ve ark. 2008). Metabolik yan etkileri açısından da dikkatli olunmalıdır (Newcomer 2005). Bu örneklemde de ketiyapin BAB'taki etkinliğinin yanı sıra EPS yan etkilerinin düşük olması ve sedatif etkisi bulunması nedeniyle diğer IKAP'lardan daha fazla tercih edilmiş olabilir. Risperidonun dozla ilişkili EPS ve ortostatik hipotansiyon yapıcı etkisi (Aziz ve ark. 2006); olanzapinin antikolinerjik ve metabolik yan etkileri yaşılıarda kullanımlarını kısıtlayabilmektedir (Komossa ve ark. 2010; Wooltorton 2004). Yaşlılarda demans ve BB'de, risperidon ve olanzapinin ketiyapine göre mortaliteyi daha fazla arttırdığına dair veriler de artmaktadır (Desai ve ark. 2012; Kales ve ark. 2012; Rossom ve ark. 2010).

Aripiprazol'un çok az hasta tarafından kullanıldığı gözlenmiştir (\%2). Aripiprazol sedasyon, kilo artışı, antikolinerjik etkiler, QT uzaması gibi durumlara yol açmaması ve önemli EPS, tardiv diskinezi riski bulunmamasından dolayı yaşılıarda BB tedavisi için güvenli ve etkili bir seçenek gibi durmaktadır (Madhusoodanan ve ark. 2004; Rado ve Janicak 2010). Küçük örneklemli ve açık etiketli bir çalışmada akut mani atağındaki yaşlı BB hastalarda etkili olduğu gösterilmiştir (Sajatovic ve ark. 2008).
Hastaların \%27.2' si AD kullanmakta olup tek başına $A D$ kullanan hasta bulunmamaktadır. Çalışmada geriye dönük veri kayıtları kullanıldığından hastalık atağı hakkında kesin bilgilere ulaşmak mümkün olmamakla birlikte bu hastaların depresif atakta olabileceği düşünülebilir. Bipolar depresyonda antidepresan kullanımı halen tartışmalı bir konudur (Nivoli ve ark. 2011). Bipolar depresyonun akut tedavisinde bir DDD veya atipik antipsikotik ile birlikte AD'lerin (özellikle SSGi) etkin ve güvenli olduğu bazı çalışmalarda bildirilmekle birlikte (Grunze 2008, Vieta ve ark. 2005), hızlı döngülülüğü ve manik kaymayı tetikleyebileceklerini ve bipolar depresyonda etkili olmadıklarını gösteren 
çalışmalar da vardır (Ghaemi ve ark. 2008; Sachs ve ark. 2007). Bu çalışmada hastaların en sık kullandığı antidepresanlar SSGl'lerdir. Yaşlılarda SSGI ilaçlar hiponatremiye, gastrointestinal sistem kanamalarına ve CYP450 enzim sistemi üzerinden ilaç-ilaç etkileşimlerine neden olabilmektedirler (Aziz ve ark. 2006). Çalışmada en sık kullanılan antidepresan ilaç ise sertralindir (\%11.1). Sertralin bir SSGI olup; sedatif olmaması, kardiyolojik ve antikolinerjik yan etkilerinin olmaması ve ilaç etkileşim risklerinin düşük olması nedeniyle yaşılıarda güvenle tercih edilebileceği bildirilmektedir (Gareri ve ark. 2000; Sheikh ve ark. 2004). Çalışmada trisiklik antidepresan kullanan hastaya rastlanmamıştır. Trisiklik antidepresanların maniyi ve hızlı döngülülüğü tetikleme riski yanında antikolinerjik, kardiyolojik ve sedatif yan etkileri dolayısı ile yaşılıarda kullanılmaları önerilmemektedir (Gijsman ve ark. 2004; Young ve ark. 2003).

Çalışmada sedatif/hipnotik olarak sıklıkla benzodiyazepin tercih edildiği görülmüştür. En sık tercih edilen benzodiyazepin ise orta-uzun yarı ömürlü olduğu bilinen klonazepamdır. Yaşlılarda sedasyon, bilişsel bozulma, düşme riski ve uzun erimli kullanımda bağımlılık benzodiyazepin kullanımı için önemli risklerdir (Madhusoodanan ve Bogunovic 2004). Bu nedenle tercih edilecek ise düşük dozda ve kısa süreli olarak kısa yarı ömürlü benzodiyazepinler önerilebilir (Aziz ve ark. 2006).

Bu çalışmanın özgün bir yönü de yaşı $B B$ hastalarında ilaç tedavilerine bağlı yan etkilerin ve tedavi uyumunun da araştırımış olmasıdır. Çalışmadaki hastaların \%60'a yakını yan etki bildiriminde bulunmuştur. Bildirilen başlıca yan etkiler tremor, iştah artışı, hipersomni, unutkanlık, ekstrapiramidal yan etkiler, gastrointestinal sistem yakınmaları, halsizlik, kilo artışı, baş ağrısı olup, bu bulgular yaşlı ve genç BB örneklemli diğer çalışmalar ile benzerdir (Matson ve ark. 2006; Sajatovic ve ark. 2005).

Literatürde BB için ilaç uyumsuzluğunun yaygın olduğu bildirilmiş ve ilaç uyumsuzluğu nüks, hospitalizasyon ve olumsuz gidiş ile ilişkilendirilmiştir (Perlick ve ark. 2004). Bipolar bozuklukta ilaç uyumsuzluğunun $\% 40$ civarında olduğunu bildiren çalışmalar bulunmaktadır (Lingam ve Scott 2002; Perlick ve ark. 2004). BB'de yaşlı hastaların ilaç uyumunun gençlerden daha iyi olduğu bildirilmektedir (Perlick ve ark. 2004). Antipsikotik kullanan yaşlı ve genç BB hastalarını ilaç uyumu yönünden karşılaştıran bir çalışmada yaşılıarın \%61'inin tedaviye tam uyumlu, \%19'unun kısmen uyumlu, \%20'sinin ise uyumsuz olduğu gösterilmiştir, aynı çalışmada genç hastaların \%49.5' $\mathrm{i}$ tam uyumlu, \%28.7'si ise uyumsuzdur (Sajatovic ve ark. 2007). Bu çalışmada da hastaların \%62.6'sının tedaviye uyumlu (tam uyumlu+uyumlu) olduğu bulunmuştur. Yaşlı hastaların gençlere göre tedavi uyumunun daha iyi olmasına katkı sağlayan faktörlerden biri bakım verenlerinin hastaların ilaçlarını düzenli olarak vermesi olabilir (Sajatovic ve ark. 2007).

Özetle bu çalışma, yaşlı tip-1 BB hastalarında tıpkı gençlerde ve yaşılılarda yapılan önceki çalışmalarda olduğu gibi sıklıkla kombinasyon tedavilerinin tercih edilmekte olduğunu, DDD olarak Li'nin VA kadar sık kullanıldığını, IKAP kullanımının yaygın olup en fazla ketiyapinin tercih edildiğini, SSGl'lerin nadir olmayarak kombinasyon tedavilerinde yer aldığını, en sık ise sertralinin kullanıldığını ortaya koymuştur. Ayrıca bu çalışma yaşı BB hastaları tarafından başlıca tremor, iştah artışı, hipersomni, unutkanlık, ekstrapiramidal yan etkiler, gastrointestinal sistem yakınmaları, kilo artışı, baş ağrısı gibi yan etkilerin bildirildiğini saptamış ve hastaların \%62.3'ünün tedavi uyumunun iyi olduğunu ortaya koymuştur.

Kesitsel ve geriye dönük bir kayıt tarama çalışması olması bu çalışmanın başlıca kısıtlıııkları olup, ülkemizde yaşlı BB hastalarında yapılan benzer bir çalışma olmaması ve çalışmanın natüralistik niteliği nedeniyle elde edilen veriler kıymetlidir. Yaşlı BB tedavisi ile ilgili uzunlamasına kontrollü çalışmalara ve bu çalışmaların sonuçları ile oluşturulacak tedavi kılavuzlarına, ülkemizde de yaşlılarda BB tedavisi konusunda yapılacak çok merkezli çalışmalara gereksinim vardır. 


\section{KAYNAKLAR}

Aizenberg D, Olmer A, Barak Y (2006) Suicide attempts amongst elderly bipolar patients. J Affect Disord, 91(1):91-94.

Al Jurdi RK, Marangell LB, Petersen NJ, Martinez M, Gyulai L, Sajatovic M (2008) Prescription Patterns of Psychotropic Medications in Elderly Compared to Younger Participants Who Achieved a "Recovered" Status in the Systematic Treatment Enhancement Program for Bipolar Disorder (STEP-BD). Am J Geriatr Psychiatry, 16(11):922-933.

Aziz R, Lorberg B, Tampi RR (2006) Treatments for Late-Life Bipolar Disorder. Am J Geriatr Pharmacother, 4(4):347-364.

BALANCE investigators and collaborators, Geddes JR, Goodwin GM, Rendell J, Azorin JM, Cipriani A, ve ark (2010) Lithium plus valproate combination therapy versus monotherapy for relapse prevention in bipolar I disorder (BALANCE): a randomised open-label trial. Lancet, 375(9712):385-395.

Beyer JL, Burchitt B, Gersing K, Krishnan KR (2008) Patterns of pharmacotherapy and treatment response in elderly adults with bipolar disorder. Psychopharmacol Bull, 41(1):102-114.

Bhalerao S, Seyfried LS, Kim HM, Chiang C, Kavanagh J, Kales HC (2012). Mortality risk with the use of atypical antipsychotics in laterlife bipolar disorder. J Geriatr Psychiatry Neurol, 25(1):29-36.

Cares M, Powers R (1998) Concomitant rash and blood dyscrasias in geriatric psychiatry patients treated with carbamazepine. Ann Pharmacother, 32(9):884-887.

Connolly KR, Thase ME (2011) The clinical management of bipolar disorder: a review of evidence-based guidelines. Prim Care Companion CNS Disord, 13(4).

Depp CA, Jeste DV (2004) Bipolar disorder in older adults: a critical review. Bipolar Disord, 6(5):343-367.

Desai VC, Heaton PC, Kelton CM (2012) Impact of the Food and Drug Administration's antipsychotic black box warning on psychotropic drug prescribing in elderly patients with dementia in outpatient and office-based settings. Alzheimers Dement, 8(5):453-457.
Fountoulakis KN, Vieta TE. Treatment of bipolar disorder: a systematic review of available data and clinical perspectives. Int J Neuropsychopharmacol 2008; 11(7):999-1029.

Fountoulakis KN, Vieta E, Sanchez-Moreno J, Kaprinis SG, Goikolea JM, Kaprinis GS (2005) Treatment guidelines for bipolar disorder: A critical review. Journal of Affective Disorders, 86(1):1-10.

Gareri P, Falconi U, De Fazio P, De Sarro G (2000) Conventional and new antidepressant drugs in the elderly. Prog Neurobiol, 61(4):353-396.

Ghaemi SN, Hsu DJ, Thase ME, Wisniewski SR, Nierenberg AA, Miyahara S, ve ark (2006) Pharmacological treatment patterns at study entry for the first 500 STEP-BD participants. Psychiatr Serv, 57(5):660-665.

Ghaemi SN, Wingo AP, Filkowski MA, Baldessarini RJ (2008) Longterm antidepressant treatment in bipolar disorder: meta-analyses of benefits and risks. Acta Psychiatr Scand, 118(5):347-356.

Gijsman HJ, Geddes JR, Rendell JM, Nolen WA, Goodwin GM (2004) Antidepressants for bipolar depression: A systematic review of randomized, controlled trials. Am J Psychiatry, 161(9):1537-1547.

Gildengers A, Tatsuoka C, Bialko C, Cassidy KA, Al Jurdi RK (2012) Correlates of Treatment Response in Depressed Older Adults With Bipolar Disorder. J Geriatr Psychiatry Neurol, 25(1):37-42.

Gildengers $A G$, Mulsant $B H$, Begley $A E$, McShea M, Stack JA (2005) A pilot study of standardized treatment in geriatric bipolar disorder. Am J Geriatr Psychiatry, 13(4): 319-323.

Grunze HC (2008) Switching, induction of rapid cycling, and increased suicidality with antidepressants in bipolar patients: fact or overinterpretation? CNS Spectr, 13(9):790-795.

Hirschfeld RM, Calabrese JR, Weissman MM, Reed M, Davies MA, Frye MA, ve ark (2003) Screening for bipolar disorder in the community. $\mathrm{J}$ Clin Psychiatry, 64(1):53-59.

Houston JP, Tohen M, Degenhardt EK, Jamal $\mathrm{HH}$, Liu LL, Ketter TA (2009) Olanzapine-divalproex combination versus divalproex monotherapy in the treatment of bipolar mixed episodes: a double-blind, placebo-controlled study. J Clin Psychiatry, 70(11):1540-1547. 
Juurlink DN, Mamdani MM, Kopp A, Rochon PA, Shulman KI, Redelmeier DA (2004) Druginduced lithium toxicity in the elderly: a populationbased study. J Am Geriatr Soc, 52(5):794-798.

Kales HC, Kim HM, Zivin K, Valenstein M, Seyfried LS, Chiang C, ve ark (2012) Risk of mortality among individual antipsychotics in patients with dementia. Am J Psychiatry, 169(1):71-79.

Komossa K, Rummel-Kluge C, Hunger H, Schmid F, Schwarz S, Duggan L, ve ark (2010) Olanzapine versus other atypical antipsychotics for schizophrenia. Cochrane Database Syst Rev, (3): CD006654.

Lala SV, Sajatovic M (2012) Medical and Psychiatric Comorbidities Among Elderly Individuals With Bipolar Disorder: A Literature Review. J Geriatr Psychiatry Neurol, 25(1):20-25.

Lingam R, Scott J (2002) Treatment nonadherence in affective disorders. Acta Psychiatr Scand, 105(3):164-172.

Madhusoodanan S, Bogunovic OJ (2004) Safety of benzodiazepines in the geriatric population. Expert Opin Drug Saf, 3(5):485-493.

Madhusoodanan S, Brenner R, Gupta S, Reddy H, Bogunovic O (2004) Clinical experience with aripiprazole treatment in ten elderly patients with schizophrenia or schizoaffective disorder: Retrospective case studies. CNS Spectr, 9(11):862-867.

Maina G, Albert U, Salvi V, Mancini M, Bogetto F (2007) Valproate or olanzapine add-on to lithium: an 8-week, randomized, open-label study in Italian patients with a manic relapse. J Affect Disord, 99(13):247-251.

Matson JL, González ML, Smith KR, Terlonge C, Thorson RT, Dixon DR (2006) Assessing side effects of pharmacotherapy treatment of bipolar disorder: A 20-year review of the literature. Res Dev Disabil, 27(5):467-500.

Moorhead SR, Young AH (2003) Evidence for a late onset bipolar-I disorder sub-group from 50 years. J Affect Disord, 73(3):271-277.

Newcomer JW (2005) Second-generation (atypical) antipsychotics and metabolic effects: a comprehensive literature review. CNS Drugs, 19 (Suppl 1): 1-93.

Nivoli AM, Colom F, Murru A, Pacchiarotti I, Castro-Loli P, González-Pinto A, ve ark (2011)
New treatment guidelines for acute bipolar depression: a systematic review. J Affect Disord, 129(1-3):14-26

Onder G, Pedone C, Landi F, Cesari M, Della Vedova C, Bernabei R, ve ark (2002) Adverse drug reactions as cause of hospital admissions: results from the Italian Group of Pharmacoepidemiology in the Elderly (GIFA). J Am Geriatr Soc, 50(12):19621968.

Oostervink F, Boomsma MM, Nolen WA, EMBLEM Advisory Board (2009) Bipolar disorder in the elderly: different effects of age and of age of onset. J Affect Disord, 116(3):176-183.

Perlick DA, Rosenheck RA, Kaczynski R, Kozma L (2004) Medication non-adherence in bipolar disorder: a patient centered review of research findings. Clin Approaches Bipolar Disord, 3(2):56-64.

Pollock BG (1999) Adverse drug reactions of antidepressants in elderly patients. $J$ Clin Psychiatry, 60 (suppl.20): 4-8.

Rado J, Janicak PG (2010) Aripiprazole for late-life schizophrenia. Clin Interv Aging, 7(5):253258.

Regier DA, Farmer ME, Rae DS, Myers JK, Kramer M, Robins LN, ve ark (1993) One-month prevalence of mental disorders in the United States and sociodemographic characteristics: the Epidemiologic Catchment Area study. Acta Psychiatr Scand, 88(1): 35-47.

Ritchie C (2008) Psychopharmacology in the elderly. In Oxford Textbook of Old Age Psychiatry, Jacoby R, Oppenheimer C, Dening T, Thomas A (eds). 4th edition. Oxford: Oxford University Press, s.193-200.

Rossom RC, Rector TS, Lederle FA, Dysken MW (2010) Are all commonly prescribed antipsychotics associated with greater mortality in elderly male veterans with dementia? J Am Geriatr Soc, 58(6):1027-1034.

Sachs GS, Nierenberg AA, Calabrese JR, Marangell LB, Wisniewski SR, Gyulai L, ve ark (2007)Effectiveness of adjunctive antidepressant treatment for bipolar depression. N Engl J Med, 356(17):1711-1722.

Sajatovic M (2002) Aging-related issues in bipolar disorder: a health services perspective. J Geriatr Psychiatry Neurol, 15(3):128-133. 
Sajatovic M, Blow FC, Kales HC, Valenstein M, Ganoczy D, Ignacio RV (2007) Age comparison of treatment adherence with antipsychotic medications among individuals with bipolar disorder. Int J Geriatr Psychiatry, 22(10):992-998.

Sajatovic M, Calabrese JR, Mullen J (2008) Quetiapine for the treatment of bipolar mania in older adults. Bipolar Disord, 10(6): 662-671.

Sajatovic M, Coconcea N, Ignacio RV, Blow FC, Hays RW (2008) Aripiprazole therapy in 20 older adults with bipolar disorder: a 12-week, openlabel trial. J Clin Psychiatry, 69:41-46.

Sajatovic M, Gildengers A, Al Jurdi RK, Gyulai L, Cassidy KA, Greenberg RL, ve ark (2011) Multisite, open-label, prospective trial of lamotrigine for geriatric bipolar depression: a preliminary report. Bipolar Disord, 13(3):294-302.

Sajatovic M, Gyulai L, Calabrese JR, Thompson TR, Wilson BG, White R, ve ark (2005) Maintenance treatment

outcomes in older patients with bipolar I disorder. Am J Geriatr Psychiatry, 13(4):305-311.

Schneeweiss S, Setoguchi S, Brookhart A, Dormuth C, Wang PS (2007) Risk of death associated with the use of conventional versus atypical antipsychotic drugs among elderly patients. CMAJ, 176(5):627-632.

Schneider L, Dagerman K, Insel P (2005) Risk of death with atypical antipsychotic drug treatment for dementia: meta-analysis of randomized placebocontrolled trials. JAMA, 294(15):1934-1943.

Sheikh Jl, Cassidy EL, Doraiswamy PM, Salomon RM, Hornig M, Holland PJ ve ark (2004) Safety and tolerability of sertraline in patients with late-life depression and comorbid medical illness J Am Geriatr Soc, 52(1):86-92.

Shulman KI (2010) Lithium for older adults with bipolar disorder: Should it still be considered a firstline agent? Drugs Aging, 27(8):607-615.

Shulman KI, Rochon P, Sykora K, Anderson G, Mamdani M, Bronskill S, ve ark (2003) Changing prescription patterns for lithium and valproic acid in old age: shifting practice without evidence. BMJ, 326(7396):960-961.

Subramaniam H, Dennis MS, Byrne EJ (2007) The role of vascular risk factors in late onset bipolar disorder. Int J Geriatr Psychiatry, 22(8):733-737.
Suppes T, Dennehy EB, Hirschfeld RM, Altshuler LL, Bowden CL, Calabrese JR, ve ark (2005) The Texas implementation of medication algorithms: update to the algorithms for treatment of bipolar I disorder. J Clin Psychiatry, 66(7):870-886.

Suppes T, Vieta E, Liu S, Brecher M, Paulsson B; Trial 127 Investigators (2009) Maintenance treatment for patients with bipolar I disorder: results from a north american study of quetiapine in combination with lithium or divalproex (trial 127). Am J Psychiatry, 166(4):476-488.

T.C. İlaç ve Eczacılık Genel Müdürlüğü: http://www.iegm.gov.tr

Tohen M, Zarate CA Jr. Antipsychotic agents and bipolar disorder. J Clin Psychiatry 1998; 59 (Supp. 1): 38-48.

Unutzer J, Simon G, Pabiniak C, Bond K, Katon W (1998) The treated prevalence of bipolar disorder in a large staff-model HMO. Psychiatr Serv, 49(8):1072-1078.

US Food and Drug Administration (FDA) (2005) Deaths With Antipsychotics in Elderly Patients With Behavioral Disturbances, in Public Health Advisory. US Department of Health and Human Services.

Vahip S (2010) Depresif Dönemin Sağaltımı. İki Uçlu Bozukluk Sağaltım Kılavuzu, Aydemir Ö, Uluşahin A, Akdeniz $F$ (eds), İkinci sürüm, Ankara: Tuna Matbaacılık, s.41-62.

Vasudev A, Thomas A (2010) Bipolar disorder' in the elderly: What's in a name? Maturitas, 66(3):231-235.

Vieta E, Nolen WA, Grunze H, Licht RW, Goodwin GA (2005) European perspective on the Canadian guidelines for bipolar disorder. Bipolar Disord, 7 (Suppl 3):73-76.

Wang PS, Schneeweiss S, Avorn J, Fischer MA, Mogun H, Solomon DH, ve ark (2005) Risk of death in elderly users of conventional vs. atypical antipsychotic medications. $\mathrm{N}$ Engl $\mathrm{J}$ Med, 353(22):2335-2341.

Wooltorton E (2004) Olanzapine (Zyprexa): Increased incidence of cerebrovascular events in dementia trials. CMAJ, 170(9):1395.

Yatham LN, Kennedy SH, O'Donovan C, Parikh SV, MacQueen G, Mclntyre RS, ve ark (2006) Canadian Network for Mood and Anxiety Treatments (CANMAT) guidelines for the 
management of patients with bipolar disorder: update 2007. Bipolar Disord, 8(6):721-739.

Young RC, Jain H, Kiosses DN, Meyers BS (2003) Antidepressant-associated mania in late life. Int J Geriatr Psychiatry, 18(5):421-424

Young RC, Gyulai L, Mulsant BH, Flint A, Beyer J (2004) Pharmacotherapy of bipolar disorder in old age: Review and recommendations. Am J Geriatr Psychiatry, 12(4):342-357.

Young RC (2005) Evidence-based pharmacological treatment of geriatric bipolar disorder. Psychiatr Clin North Am 2005; 28(4):837869.

Young RC, Kiosses D, Heo M, Schulberg HC, Murphy C, Klimstra S, ve ark (2007) Age and ratings of manic psychopathology. Bipolar Disord, 9(3):301-304.

Young RC, Schulberg HC, Gildengers AG, Sajatovic M, Mulsant BH, Gyulai L, ve ark. (2010) Conceptual and methodological issues in designing a randomized, controlled treatment trial for geriatric bipolar disorder: GERI-BD. Bipolar Disord 2010: 12: 56-67. 